\title{
Epistaxis Complicated by Hemolacria: A Case Report
}

\author{
Anne E. Drake, BA and Clifford D. Packer, MD
}

\begin{abstract}
Hemolacria is a rare complication of epistaxis treated with nasal compression or tamponade. We report the case of a man, aged $8 \mathrm{I}$ years, with end-stage renal disease who developed hemolacria after insertion of a "Rhino Rocket" nasal tamponade device to treat persistent epistaxis. The hemolacria resolved after treatment with intranasal oxymetazoline. In the setting of epistaxis with nasal tamponade, hemolacria is thought to be caused by retrograde flow from the inferior nasal turbinates via an anatomic connection with the lacrimal system, with passage through the valves of Hasner and Rosenmüller to the lacrimal ducts. Hemolacria is very rare even in severe cases of epistaxis; we postulate that only patients with either congenital absence or acquired incompetence of the lacrimal valves are predisposed to hemolacria after treatment of epistaxis with a tamponade device. Physicians should be aware that hemolacria in the setting of epistaxis is usually a self-limited condition that can be treated with conservative measures to control nasal hemorrhage.
\end{abstract}

Keywords: Hemolacria; Nasolacrimal duct; Anatomy

$\mathrm{H}$ emolacria, or "bloody tears," is a rare clinical condition that has been described primarily in case reports. ${ }^{1-17}$ According to a comprehensive historical review of hemolacria by Murube, ${ }^{2}$ the first mention of bloody tears in the medical literature was in the sixth century AD, and numerous cases have been reported since the beginning of the nineteenth century.

We report a case of hemolacria in a patient with epistaxis treated with anterior nasal tamponade using a "Rhino Rocket" nasal packing device. The hemolacria resolved after treatment with intranasal oxymetazoline.

\section{Case}

An African-American man, aged 81 years, with past medical history significant for coronary artery disease status-post 3-vessel CABG and end-stage renal disease on hemodialysis presented with 3 days of intermittent epistaxis. He was taking aspirin $81 \mathrm{mg}$ daily as prescribed; he was not on any anticoagulant medication, and his INR, PTT, and platelet count were normal on admission. The bleeding occurred spontaneously, with no history of surgery or trauma to the nose or face. He experienced two episodes of epistaxis that lasted under 30 minutes and were relieved with external pressure. However, a third episode began several hours after the second and continued despite persistent pressure, with blood oozing from the right nostril continuously. He was admitted to the hospital for continued management of the epsitaxis.

A "Rhino Rocket" nasal packing device was placed in the right nostril on the ward by an otolaryngologist, with instructions to use gauze packing to the anterior nares as needed. The patient had continued oozing from the right nostril, but was otherwise stable with normal vital signs and no other complaints. The "Rhino Rocket" packing had been in place for approximately 15 hours when the patient's nurse noticed a small amount of blood in the medial corner of the right eye at the lacrimal puncta, which quickly progressed to frank hemolacria. A "rapid response" alert was called by the
Corresponding Author: Anne Drake, BA, Case Western Reserve University School of Medicine, Health Education Campus, 950I Euclid Ave, Cleveland, OH 44I 06 Tel: (248) 4I3-7004,Email:Aed65@case.edu
Received: March 18, 2020

Revised: May 18, 2020

Accepted: June 12, 2020

doi: $10.3121 / \mathrm{cmr} .2020 .1566$ 
nurse. The patient remained hemodynamically stable. He denied any changes in vision, pain in the eye, or blurry vision. Per ENT recommendations, oxymetazoline-soaked gauze was placed into the right nostril, with rapid resolution of the hemolacria. The patient was seen the next day for removal of the nasal packing and then had successful cautery of the bleeding vessel. At discharge, the patient was advised to stay off the aspirin until his follow-up in the ENT clinic.

\section{Discussion}

Etiologies of hemolacria can include retrograde epistaxis, surgical or other trauma to the lacrimal system, conjunctival hemorrhage, lacrimal sac tumors or infections, hereditary hemorrhagic telangiectasias, and aberrant microvascular endometrial tissue causing bleeding into the lacrimal basin (vicarious menstuation). ${ }^{1,2}$ Conjunctival hemorrhages can be caused by trauma, conjunctivitis, conjunctival ulcers, telangiectasias, hemangiomas, conjunctival varices, and tumors; the lid rim has also been reported as a site of hemolacria in a case of blepharoconjunctivitis. ${ }^{2}$ Hemolacria secondary to retrograde epistaxis (as suspected in our case) has been reported in patients with epistaxis and increased pressure within the nasal cavity, which can be caused by nasal packing as well as by pinching or blowing the nose. ${ }^{3,4}$ Blood emerging through the lacrimal punctum is most frequently a result of retrograde epistaxis, but can also be caused by tumors, foreign bodies, or contusive trauma. In the absence of nasal packing or other forms of nasal obstruction, it is generally assumed that the bleeding is the result of extravasation in the lacrimal pathways rather than epistaxis with retrograde flow. ${ }^{2}$ No case reports were identified in the literature in which hemolacria preceded epistaxis, which suggests that hemolacria in the setting of retrograde epistaxis is a secondary outcome rather than a primary presenting symptom.

In the case of retrograde epistaxis, the underlying cause is thought to be the anatomic connection between the inferior nasal turbinates and the lacrimal system. In the setting of epistaxis with tamponade, blood pools in the inferior turbinate of the nasal fossae. From this area it can ascend through the Valve of Hasner into the nasolacrimal duct and lacrimal sac, pass through the valve of Rosenmüller, and then extrude through the lacrimal canaliculi and enter the eye as bloody tears via the lacrimal puncta $^{5}$ (see Figure 1). If the source of the epistaxis is distal to the Valve of Hasner, a significant arterial hemorrhage is likely, and nasal tamponade may theoretically cause the valve to become incompetent and result in a retrograde nasolacrimal hemorrhage. ${ }^{5}$ Hemolacria, however, is rare; it does not occur in most patients with epistaxis, even those with severe arterial hemorrhage treated with nasal tamponade. This raises the question of whether there is a rare anatomic anomaly that might increase the risk for hemolacria. Incompetency of the valve of Hasner is

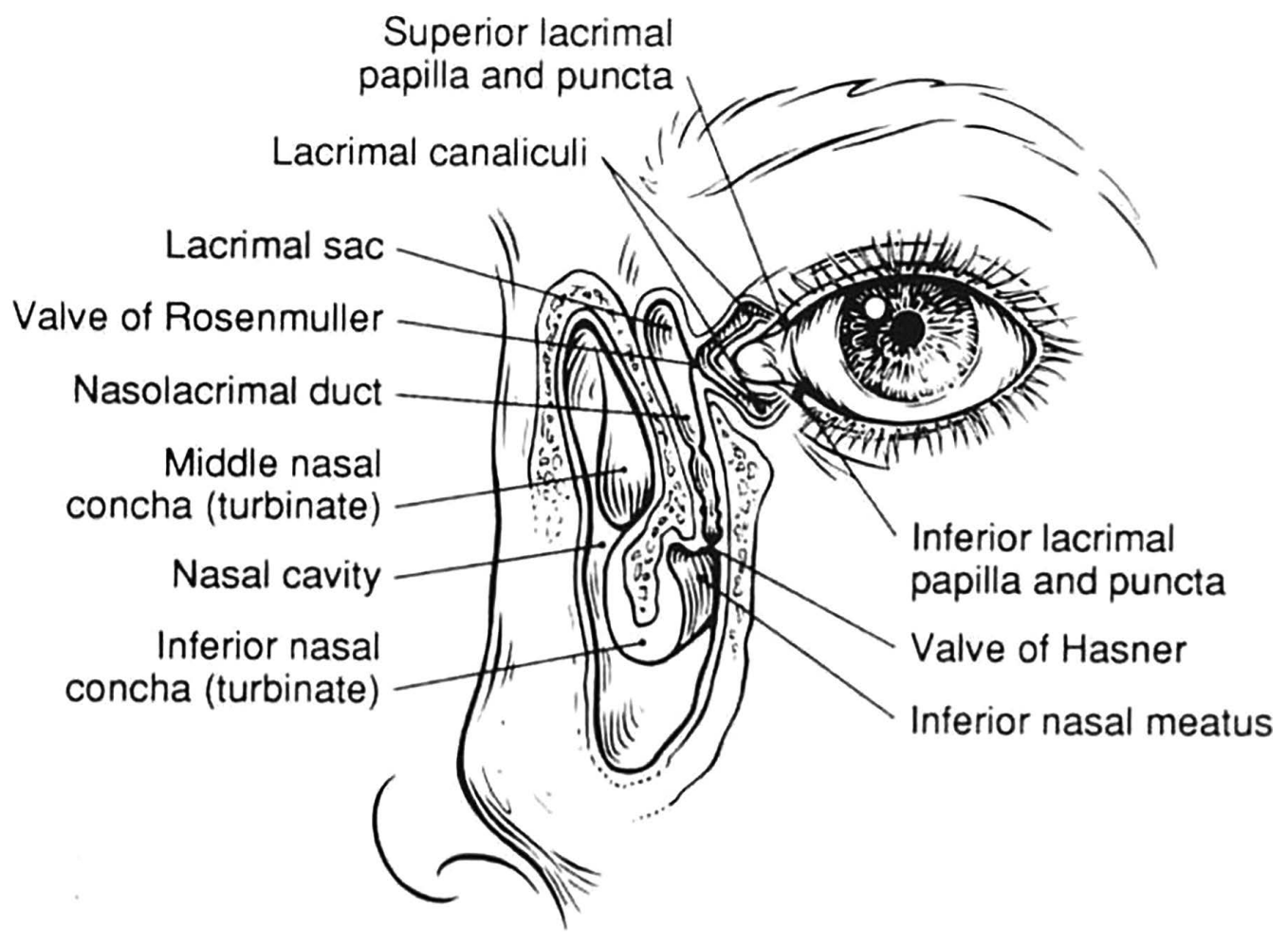

Figure 1. Anatomy of the nasolacrimal system. Note the position of the lacrimal puncta, valve of Rosenmuller, nasolacrimal duct, and the valve of Hasner. ${ }^{21}$ Reproduced with permission. Meyer, et al. AJNR Am J Neuroradiol. 1993;14(4):1008-1010. Copyright $(1993$ American Society of Neuroradiology. All rights reserved. 
usually congenital, but may also occur in cases of surgical or accidental trauma to the orifice of the nasolacrimal duct, or from nasal infection. ${ }^{18}$ According to Duke-Elder, about $5 \%$ of persons can "whistle through their eyes, as it were, when air is forcibly exhaled with the nose closed."18 Tanenbaum and McCord note that for patients with congenital absence of both the valve of Hasner and the valve of Rosenmüller, "it is possible to blow air from the nose into the eye, and nosebleeds may produce bloody tears." 19 We postulate that only patients with congenital absence or incompetence of the valves of Hasner and Rosenmüller are predisposed to develop hemolacria in the setting of epistaxis treated with nasal tamponade. This could explain the rarity of hemolacria as a complication of epistaxis in the general population. In the case of our patient who had no prior history of hemolacria or (presumably) whistling through the eyes, incompetence of the lacrimal valves could have played a significant role in the development of hemolacria. While the nasolacrimal valvular system has never been studied in isolation in terms of age, venous valvular incompetence is known to increase with increasing age and findings can likely be extrapolated to include valves of other systems (Figure 1). ${ }^{20}$

\section{Conclusion}

Hemolacria is a rare complication of epistaxis, and usually occurs in patients treated with nasal tamponade. Patients with congenital absence or incompetence of the valves in the nasolacrimal duct may be predisposed to hemolacria when they develop epistaxis. While this condition is relatively wellknown to otolaryngologists, primary care physicians and hospitalists may be mystified and alarmed when patients with epistaxis develop hemolacria. Physicians should be aware that hemolacria in the setting of epistaxis is usually a self-limited condition that can be treated conservatively with intranasal decongestants or other measures to control nasal hemorrhage.

\section{References}

1. Özcan KM, Özda? T, Baran H, Ozdogan F, Dere H. Hemolacria: Case report. Int J Pediatr Otorhinolaryngol. 2013;77(1):137-138.

2. Murube J. Bloody tears: historical review and report of a new case. Ocul Surf. 2011;9(3):117-125.

3. Wieser S. Bloody tears. Emerg Med J. 2012;29(4):286.

4. Wiese MF. Bloody tears, and more! An unusual case of epistaxis. Br J Ophthalmol. 2003;87(8):1051.

5. Humber CC, Lanigan DT, Hohn FI. Retrograde hemorrhage (hemolacria) from the lacrimal puncta after a Le Fort I osteotomy: a report of 2 cases and a review of the literature. J Oral Maxillofac Surg. 2011;69(2):520-527.

6. Khanna RK, Fontaine A, Lemacon JM, Moriniere S, Pisella PJ. Hemolacria revealing a primary nasolacrimal duct melanoma. Can J Ophthalmol. 2019;54(2):e70-e73.

7. Audelan T, Best AL, Ameline V. Hémolacrie, à propos d'un cas pédiatrique [Hemolacria: A pediatric clinical case report]. J Fr Ophtalmol. 2019;42(1):e15-e17.

8. Di Maria A, Famà F. Hemolacria - crying blood. N Engl J Med. 2018;379(18):1766.

9. Manzano G, Shantharam R, Webb E, Finelt N, Hengel K. Case 2: Hemolacria, hematochezia, and hematuria in an 11-month-old boy. Pediatr Rev. 2018;39(8):418-420.
10. Ali MJ, Naik MN. Dacryoendoscopy in a case of unexplained hemolacria. Ophthal Plast Reconstr Surg. 2018;34(6):e213.

11. Chon BH, Zhang R, Bardenstein DS, Coffey M, Collins AC. Bloody epiphora (hemolacria) years after repair of orbital floor fracture. Ophthal Plast Reconstr Surg. 2017;33(5):e118-e120.

12. Sobol EK, Barmettler A. A case of idiopathic bilateral hemolacria in an 11-year-old girl. Ophthal Plast Reconstr Surg. 2017;33(4):e98-e99.

13. Maurin O, Arvis AM, Lemoine S. Hémolacrie sur poussée hypertensive [Hemolacria in hypertensive crisis]. Rev Prat. 2015;65(9):1167.

14. Praveen BK, Vincent J. Hematidrosis and hemolacria: a case report. Indian J Pediatr. 2012;79(1):109-111.

15. Mukkamala K, Gentile RC, Rao L, Sidoti PA. Recurrent hemolacria: a sign of scleral buckle infection. Retina. 2010;30(8):1250-1253.

16. Das D, Kumari P, Poddar A, Laha T. Bleeding to life: a case series of hematohidrosis and hemolacria. Indian J Pediatr. 2020;87(1):84.

17. Billoir P, Feugray G, Chrétien MH 5th, Fresel M, Le Cam Duchez V. Quel bilan devant une haemolacria? À propos d'un cas et revue de la littérature [Bloody tears: About a case and a review of the literature]. Rev Med Interne. 2020;41(5):339-342.

18. Levitt JM, Kravitz D. Lacrimal air anomalies. Arch Ophthalmol. 1959;61(1):9-13.

19. Tanenbaum M, McCord CD Jr. 2006. Chapter 13: Lacrimal drainage system. Duane's Clinical Ophthalmology. Philadelphia: Lippincott Williams \& Wilkins. URL: http:/www.oculist.net/ downaton502/prof/ebook/duanes/pages/v4/v4c013.html (accessed 21 Jan. 2020).

20. Callam MJ. Epidemiology of varicose veins. Br J Surg. 1994;81(2):167-173.

21. Meyer JR, Quint DJ, Holmes JM, Wiatrak BJ. Infected congenital mucocele of the nasolacrimal duct. AJNR Am J Neuroradiol. 1993;14(4):1008-1010.

\section{Author Affiliations}

Anne E. Drake, BA*; Clifford D. Packer, $M D^{*}, \dagger$

*Case Western Reserve University School of Medicine, Cleveland, $\mathrm{OH}$ †VA Medical Center, Cleveland, $\mathrm{OH}$ 